\title{
Cervical Intra-Epithelial Neoplasia: Index of Papillomavirus Infection and Histopathological Grade in Lubumbashi Patients
}

\author{
Mwenze Didier ${ }^{1}$, , Kyabu Veronique ${ }^{1}$, Mukalay Abdon ${ }^{2}$, Kalenga Prosper ${ }^{3}$, Ilunga Julien ${ }^{1}$ \\ ${ }^{1}$ Department of Pathology, University of Lubumbashi, Lubumbashi, Democratic Republic of Congo \\ ${ }^{2}$ Department of Public Health, University of Lubumbashi, Lubumbashi, Democratic Republic of Congo \\ ${ }^{3}$ Department of Gynecology Obstetrics, University of Lubumbashi, Lubumbashi, Democratic Republic of Congo
}

Email address:

mwenze.mwadi@gmail.com (M. Didier)

${ }^{*}$ Corresponding author

To cite this article:

Mwenze Didier, Kyabu Veronique, Mukalay Abdon, Kalenga Prosper, Ilunga Julien. Cervical Intra-Epithelial Neoplasia: Index of Papillomavirus Infection and Histopathological Grade in Lubumbashi Patients. International Journal of Clinical Oncology and Cancer Research. Vol. 4, No. 3, 2019, pp. 29-33. doi: 10.11648/j.ijcocr.20190403.11

Received: August 13, 2019; Accepted: September 5, 2019; Published: September 18, 2019

\begin{abstract}
The aim of this study is to show the relationship between the index of Papillomavirus infection and the grade of cervical intraepithelial neoplasia as proposed by WHO in Lubumbashi patients. This is a cross-sectional analytical study on cervical biopsies whose histological diagnosis is an intraepithelial neoplasia registered in two Laboratory of Patholoy in Lubumbashi for a period of two years from June 2017 to June 2019. The following results were observed: A total of 41 cases of intraepithelial neoplasia were recorded out of 91 cervical biopsies is $43.2 \%$. Five indices of Human Papillomavirus infection are found in Lubumbashi patients in variable proportions without statistically significant difference; that is the index (5) in $29.27 \%$, the indices (7) and (9) in $21.95 \%$ for each index, the index (6) in $17.07 \%$ and the index (8) in $9.76 \%$. The three grades of intraepithelial neoplasia proposed by the WHO since 2003 are also found in Lubumbashi patients in varying proportions with no statistically significant difference; $48.78 \%$ for grade $3 ; 36.59 \%$ for grade 2 and $14.63 \%$ for grade 1 . There is no relationship between the HPV infection index and the grade of cervical intraepithelial neoplasia; calculated linear correlation $\mathrm{r}$ $\wedge 2$ is equal to 0.00 .
\end{abstract}

Keywords: Papillomavirus Index, Intra-Epithelial Neoplasia, Grade

\section{Introduction}

The persistence of high-carcinogenic Papillomavirus infection (HPV genotypes: 16, 18, 31, 33, 35, 39, 45, 51, $52,58,56,59)$ leads the cytological and histological alterations of the squamous epithelium cervical [1-3]. These alterations are called in several ways either epithelial dysplasia of the cervix or precancerous lesions of the cervix or intraepithelial neoplasia of the uterine cervix [4-6]. Their progressive progression goes through three grades before crossing the basement membrane and turning into an invasive carcinoma of the cervix [7]. Several classifications have proposed the grades of intraepithelial neoplasia [3]. The first classification was that of Papanicolaou in 1943, it was based solely on cytology. It has been used for many years, but it is relatively inaccurate [8]. In 1973 the World Health Organization proposed the histological classification which included 5 entities: the condyloma without dysplasia, the light dysplasia, the moderate dysplasia, the severe dysplasia and the carcinoma in situ (3). The main insufficiency of this classification was the difficulty or impossibility of dissociating severe dysplasia or carcinoma in situ. The cytological classification of Bethseda was developed in 1988 and revised in 2001. It introduces glandular lesions and squamous lesions of undetermined significance and is still used today as a cytological classification [3, 8]. Since 1967, Richart has developed a histological classification that has been used the most, some authors continue to used it until today [3]. 
The World Health Organization has proposed the current histological classification since 2003, which has 3 grades, based on the thickness of the squamous epithelium with cyto-histological abnormalities such as anysocaryosis, anysocytosis, numerous abnormal mitoses, loss of polarity and cytoplasmic atypism [9]. Grade 1 is defined by tissue alterations only affect less than the lower third of the epithelial layer; in the altered zone the cells have lost their polarity, and show cytonuclear atypisms. Grade 2 is characterized by the presence of histological changes in more than half of the epithelial layer. The upper third contains well differentiated cells that retain their polarity and good differentiation. Grade 3 shows tissue alterations of interest to cells in almost all epithelial layers. The basement lamina remains intact $[9,10]$. The alterations induced by Papillomavirus infection allowed the ParisTolbiac consensus in 1991 to define the index of Papillomavirus infection in this way: Koilocytosis defines by the presence of a light perinuclear halo has an index of (4). Bi nucleation is the presence of two nuclei in the same cell at the index of (2). The intraepithelial capillaries which are vascular structures formed within the epithelium, acanthosis which consists of hyperplasia of the epithelium, dyskeratosis, which is abnormal keratinization, basal layer hyperplasia, and exaggerated stratification of the basal layer of the epithelium, each having an index of (1) [11-13]. Although the histological criteria for grade establishment of intraepithelial neoplasia as proposed by the WHO are known; until today, there are difficulties in establishing the histological grade of intraepithelial neoplasia of the cervix $[14,15]$. Indeed, for several authors the histological grade is not reproducible when using more precise techniques such as the expression of p16 INKa and Ki-67 [16-19]. Other authors show a risk of under-diagnosis respectively of 29 and $22 \%$ (CIN2 + diagnosed as normal biopsy or CIN1), and a risk of on diagnosis of respectively 3 and $28 \%$ (CIN 1 diagnosed as CIN2 +) $[14,15]$. Until now, no study has considered that cyto-histological alterations recognized to be induced by Papillomavirus infection to establish the histological grade of cervical neoplasia in patients living in Lubumbashi in Democratic Republic of Congo. This study aims to determine the index of papillomavirus infection and the histological grade of intraepithelial neoplasia of the cervix in Lubumbashi patients. It also aims to establish the relationship that exists between this index and this rank.

\section{Method}

\subsection{Type of Study}

This is a cross-sectional analytical study based on the analysis of cervical biopsies bearing the diagnosis of intraepithelial neoplasia recorded in two Laboratory of Pathology of Lubumbashi (Laboratory of University Hospital of Lubumbashi and the laboratory of the Congolese League
Against Cancer) for a period of 2 years from June 2017 to June 2019.

\subsection{Selection of Cases}

The patients were selected from a total of 95 patients with cervical lesions by a non-exhaustive sampling taking into account all cases of cervical biopsy bearing as diagnostic intraepithelial neoplasia of the cervix recorded in two laboratories during the period of our study. Subsequently, we selected all the slides of these biopsies for an examination by optical microscope.

\subsection{Inclusion Criteria}

All patients diagnosed with cervical intraepithelial neoplasia regardless of the grade according to the histological classification criteria proposed by the WHO in $2003[9,10]$ were included in this study for a total of 41 cases.

\subsection{Exclusion Criteria}

Patients whose cervical biopsies revealed invasive carcinoma or a tumor of the columnar or glandular epithelium or cervicitis were excluded from this study, for a total of 54 cases.

\subsection{Histology Treatment}

The process of tissue treatment was as followed:

1. Fixation in neutral formaldehyde solution at $10 \%$ dilution for 24 hours.

2. Dehydration in 4 baths of ethanol at $60^{\circ}, 80^{\circ}, 95^{\circ}$ and $100^{\circ}$ concentration.

3. Lightening in 2 baths of xylene each lasting one hour.

4. Stay in paraffin liquid kept in oven at $60^{\circ} \mathrm{C}$ for 24 hours.

5. Inclusion of tissue using an automatic coating station.

6. Cutting of paraffin blocks with a microtome of Minot model.

7. Staining using usual method of hematoxylin-eosin.

\subsection{Measuring the Index of Papillomavirus Infection}

Measurement of the index of Papillomavirus infection was made at the Laboratory of Hospital University of Lubumbashi by microscopic re-examination of all intraepithelial neoplasia slides of the cervix according to the cyto-histological criteria proposed in the consensus from Paris-Tolbiac in 1991 giving an index to each histological parameter namely koilocytosis (index 4), bi nucleation (2), dyskeratosis (1), the presence of intraepithelial capillaries (1), layer hyperplasia basal (1) and acanthosis (1) [11-13].

\subsection{Histological Grade}

The histological grade was established by 3 pathologists from Laboratory of Hospital University of Lubumbashi, following the classification criteria for intraepithelial neoplasia proposed by WHO in 2003. All 3 grades were 
selected; grade 1 when the tissue changes only affect less than the lower third of the epithelial layer; grade 2 when histological changes are in more than half of the epithelial layer; grade 3 if tissue damage affects cells in almost all epithelial layers $[9,10]$.

\subsection{Parameters}

There is the age of the patient, the index of Papillomavirus infection and the histological grade of intraepithelial neoplasia.

\subsection{Statistical Analyzes}

Statistical analyzes were performed on a Compaq CQ58 computer. The Epi Info 2011 software was used for encoding and data processing. Mean with standard deviation, proportions expressed as a percentage were calculated. The 95\% confidence Limits and the linear correlation coefficient were used to compare the results.

\section{Results}

\subsection{Frequency of Intraepithelial Neoplasia}

The frequency of intraepithelial neoplasia recorded in this study was 41 cases out of 95 biopsies of the cervix or $43.2 \%$.

\subsection{Age of Patient}

The mean age of 41 patients selected in this study was 45.3 \pm 9.6 years. The extremes were 24 to 76 years old.

\subsection{Index of Papillomavirus Infection}

Papillomavirus indices found in this study ranged from 5 to 9 in various proportion. At the $95 \%$ confidence interval. These proportions are not statistically different. Or $29.27 \%$ $(95 \% \mathrm{CI}=16.13-45.54)$ for the index $(5) ; 21.95 \%(95 \% \mathrm{CI}=$ 10.56-37.61) respectively for the index (7) and the index (9); $17.07 \%(95 \% \mathrm{CI}=7.15-32.06)$ for the index (6) and $9.76 \%$ $(95 \% \mathrm{CI}=2.72-23.13)$ for the index (8). Table 1 illustrates these observations.

Table 1. Index of Papillomavirus infection according to the Paris-Tolbiac consensus $(n=41)$.

\begin{tabular}{llll}
\hline Indix HPV & Number & \% & 95\% Conf Limits \\
\hline 5 & 12 & $29.27 \%$ & $(16.13 \%-45.54 \%)$ \\
7 & 9 & $21.95 \%$ & $(10.56 \%-37.61 \%)$ \\
9 & 9 & $21.95 \%$ & $(10.56 \%-37.61 \%)$ \\
6 & 7 & $17.07 \%$ & $(7.15 \%-32.06 \%)$ \\
8 & 4 & $9.76 \%$ & $(2.72 \%-23.13 \%)$ \\
Total & 41 & $100.00 \%$ & \\
\hline
\end{tabular}

\subsection{Grade of Intraepithelial Neoplasia}

All 3 grade of intraepithelial neoplasia were found in this study and have non-identical frequency without statistically significant difference at the $95 \%$ confidence interval; ie $48.78 \%$ (95\% CI $=32.88-64.87)$ for $\mathrm{CIN} 3,36.59 \%$ (95\% CI $=22.12-53.06)$ for CIN 2 and $14.63 \%(95 \% \mathrm{CI}=5.57-29.17)$ for CIN1. Table 2 illustrates these observations.

Table 2. Grade of Intraepithelial Neoplasia According to WHO 2004 ( $n=$ 41).

\begin{tabular}{llll}
\hline Grade & Number & \% & 95\% Conf Limits \\
\hline CIN3 & 20 & $48.78 \%$ & $(32.88 \%-64.87 \%)$ \\
CIN2 & 15 & $36.59 \%$ & $(22.12 \%-53.06 \%)$ \\
CIN1 & 6 & $14.63 \%$ & $(5.57 \%-29.17 \%)$ \\
Total & 41 & $100.00 \%$ & \\
\hline
\end{tabular}

CIN (Cervical intra-epithelial neoplasia).

\subsection{Correlation Between the Index of HPV Infection and the Grade of Neoplasia}

The index of HPV infection does not influence the grade of intraepithelial neoplasia. The correlation coefficient $\mathrm{r}^{\wedge} 2$ calculated is equal to 0.00 .

\section{Discussion}

\subsection{Frequency of Intraepithelial Neoplasia}

This study shows that out of a total of 95 women with cervical lesions in Lubumbashi; 41 of them are those who have intraepithelial neoplasia of the cervix of the uterus is a frequency of $43.2 \%$. In a study conducted in India out of a total of 84 women who underwent cervical biopsy, intraepithelial neoplasia was reported in 49 cases, or $58.3 \%$ of cases [20]. These observations show that intraepithelial neoplasia is one of the common pathologies of the cervix. Population-based screening studies, however, show lower intraepithelial neoplasia rates compared to patient-only diagnostic studies. In these population-based studies, Mwenze et al had observed a frequency of cervical intraepithelial neoplasia of $13 \%$ in the Lubumbashi population [21] and Sadeghi et al found $13.31 \%$ as frequency of intraepithelial neoplasia in the population of the United States of America [22]. Other studies, however, have associated the high frequency of intraepithelial neoplasia of the cervix with various factors; either to an immunodeficiency secondary to the infection with the HIV or still to the sociodemographic conditions of population. This is notably the Wrigth et al [23] study in which the frequency of intraepithelial neoplasia is higher in HIV-positive patients than in non-HIV-infected patients, ie $20 \%$ versus $4 \%$ [24]. In China the variation in frequency of intraepithelial neoplasia was associated with the different conditions sociodemographic, $7 \%$ in rural city and $3.4 \%$ in urban city [25].

\subsection{Age of Patients}

The mean age of patients with cervical intraepithelial neoplasia in this study was $45.3 \pm 9.6$ years; with extremes ranging from 24 to 76 years. In a study conducted in the obstetrics and gynecology department of Bordeaux University Hospital, the median age of patients with intraepithelial neoplasia is 33 years with extremes ranging from 20 to 65 years [3]. In another study, the mean age of 
patients with intraepithelial neoplasia of the cervix was 39.1 \pm 3.16 years [20]. Other researchers observed an average age of 40 years for intraepithelial neoplasia of the cervix [26]. These observations show that intraepithelial neoplasia is frequently observed at an age greater than 30 years.

\subsection{Index of Papillomavirus Infection}

The index of infection varies from 5 to 9 . This variation of the index observed in patients of Lubumbashi could evoke the existence of several different genotypes of papillomavirus found in this population. Indeed, for several authors, the different HPV infection scores have been observed and are explained by the existence of several genotypes of HPV observed in the population [27-29].

\subsection{Grade of Intraepithelial Neoplasia}

All 3 grades proposed by the WHO histological classification in 2003 were found in this study in variable proportions with no statistically significant difference, ie $48.78 \%$ of cases for CIN3, 36.59\% for CIN2 and 14, $63 \%$ for CIN1. During the study conducted by Missaoui et al; all the 3 grades of intraepithelial neoplasia of the cervix were also found in non-identical proportions, ie $67.35 \%$ for CIN3, $14.3 \%$ for CIN2 and $18.35 \%$ for CIN1 [30]. Study carried out at the Bordeaux University Hospital where all 3 grades were also found, ie $33.33 \%$ for CIN 3 ; $37.5 \%$ for CIN2 and $29.17 \%$ for CIN1 [3]. These frequency variabilities observed for the different grades in the different study sites may be related to the unsatisfactory application of histological criteria for the diagnosis of precancerous lesions, which is why some authors currently suggest improving the quality of the diagnosis with new ones approaches including molecular biology methods such as the expression of biomarkers [30, 31].

\subsection{Correlation Between Papillomavirus Index and Grade of Neoplasia}

This study shows that there is no correlation between the cyto-histathological index of human papillomavirus infection and the grade of intraepithelial neoplasia. Other authors have not found this relationship, but they have observed a correlation in the other hand, they observed a correlation between the index or the score of papillomavirus infection with the expression of biomarkers [29].

\section{Conclusion}

Cervical intraepithelial neoplasia recorded in Lubumbashi has 5 indices of Papillomavirus infection ranging from (5) to (9) according to the consensus from Paris-Tolbiac in 1991 and 3 histological grades proposed by the WHO. This cytohistopathological index of Papillomavirus infection has no relation with the grade of intraepithelial neoplasia of the cervix in Lubumbashi women.

\section{References}

[1] Sand FL erke, Munk C, Frederiksen K, Junge J, Iftner T, Dehlendorff C, et al. Risk of CIN3 or worse with persistence of 13 individual oncogenic HPV types. Int J Cancer. 2019; 144 (8): 1975-1982.

[2] Bernichon E, Espenel S, Méry B, Trone J-C, Rehalia-Blanchard A, He YM, et al. Le papillomavirus: implications carcinologiques et mesures préventives. Presse Médicale. 2019.

[3] Valérie Metang Ngansop. Études des profils viraux et de la protéine $\mathrm{p} 16$ dans les néoplasies intra.txt.

[4] Parra SG, Rodriguez AM, Cherry KD, Schwarz RA, Gowen RM, Guerra LB, et al. Low-cost, high-resolution imaging for detecting cervical precancer in medically-underserved areas of Texas. Gynecol Oncol. 2019.

[5] Wright TC, Ronnett BM, Kurman RJ. Precancerous lesions of the cervix. Blausteins Pathol Female Genit Tract. 2019; 239-313.

[6] Debeaudrap P, Sobngwi J, Tebeu P-M, Clifford GM. Residual or recurrent precancerous lesions after treatment of cervical lesions in HIV-infected women: a systematic review and meta-analysis of treatment failure. Clin Infect Dis. 2019.

[7] Singh C, Kim GN. Cervical Squamous Intraepithelial Lesions: A Pathologist's Perspective. In: Preventive Oncology for the Gynecologist. Springer; 2019. p. 71-82.

[8] Boulanger J-C, Sevestre H. ASCUS: état des lieux. Gynécologie Obstétrique Fertil. 2006; 34 (1): 44-48.

[9] Eble JN, Tavassoli FA, Devilee P. Pathology and Genetics of Tumours of the Breast and Female Genital Organs. Iarc; 2003.

[10] Tavassoli FA. Pathology and genetics of tumours of the breast and female genital organs. World Hhealth Organ Classif Tumours. 2003.

[11] REYNES M, VEDRENNE C, JAUBERT F, MARTIN E. Cervical neoplasia consensus Paris-Tolbiac 1991: summary and recommandations. Arch Anat Cytol Pathol. 1991; 39 (56): 220-222.

[12] REYNES M, VEDRENNE C, JAUBERT F, MARTIN E. Consensus néoplasies du col utérin Paris-Tolbiac 1991: synthèse de recommandations. Arch Anat Cytol Pathol. 1991; 39 (5-6): 217-219.

[13] AMRANI M, LALAOUI K, ELMZIBRI M, ROUAS L, BENKIRANE L, LAMAALMI N, et al. TYPAGE PVH ET DÉPISTAGE DU CANCER DU COL DE L'UTÉRUS: RÉSULTATS D'UNE ÉTUDE CRITIQUE MAROCAINE. Maroc Méd. 2002; 24 (3).

[14] Paolo Dalla Palma MD, Rossi PG, Collina G, Buccoliero AM, Ghiringhello B, Gilioli E, et al. The Reproducibility of CIN Diagnoses Among Different Pathologists Data From Histology Reviews From a Multicenter Randomized Study. Am J Clin Pathol. 2009; 132: 125-132.

[15] Bergeron C, Ordi J, Schmidt D, Trunk MJ, Ridder R. Improving diagnostic accuracy and inter-observer agreement for CIN2+ through the conjunctive use of p16 immunohistochemistry on cervical biospies. In: LABORATORY INVESTIGATION. NATURE PUBLISHING GROUP 75 VARICK STREET, 9TH FLOOR, NEW YORK, NY 100131917 USA; 2008. p. 198A-198A. 
[16] Tringler B, Gup CJ, Singh M, Groshong S, Shroyer AL, Heinz $\mathrm{DE}$, et al. Evaluation of p16 INK4a and pRb expression in cervical squamous and glandular neoplasia. Hum Pathol. 2004 35 (6): 689-696.

[17] Van de Putte G, Holm R, Lie AK, Tropé CG, Kristensen GB. Expression of $\mathrm{p} 27, \mathrm{p} 21$, and $\mathrm{p} 16$ protein in early squamous cervical cancer and its relation to prognosis. Gynecol Oncol. 2003; 89 (1): 140-147.

[18] Sano T, Oyama T, Kashiwabara K, Fukuda T, Nakajima T. Immunohistochemical overexpression of $\mathrm{p} 16$ protein associated with intact retinoblastoma protein expression in cervical cancer and cervical intraepithelial neoplasia. Pathol Int. 1998; 48 (8): 580-585.

[19] Saito T, Nakajima T, Mogi K. Immunohistochemical analysis of cell cycle-associated proteins p 16, p Rb, p 53, p 27 and $\mathrm{Ki}$ 67 in oral cancer and precancer with special reference to verrucous carcinomas. J Oral Pathol Med. 1999; 28 (5): 226232 .

[20] Belinson J, Qiao YL, Pretorius R, Zhang WH, Elson P, Li L, et al. Shanxi Province Cervical Cancer Screening Study: a cross-sectional comparative trial of multiple techniques to detect cervical neoplasia. Gynecol Oncol. 2001; 83 (2): 439444.

[21] Didier M, Phillipe M, Abdon M, Julien I. Cervical smears: morphological and epidemiological study for intra-epithelial neoplasia in Lubumbashi. Int J Clin Oncol Cancer Res. 2018; 3 (4): 55-58.

[22] Sadeghi SB, Hsieh EW, Gunn SW. Prevalence of cervical intraepithelial neoplasia in sexually active teenagers and young adults: results of data analysis of mass Papanicolaou screening of 796, 337 women in the United States in 1981. Am J Obstet Gynecol. 1984; 148 (6): 726-729.

[23] Wright JT, Ellerbrock TV, Chiasson MA, Van ND, Sun X-W. Cervical intraepithelial neoplasia in women infected with human immunodeficiency virus: prevalence, risk factors, and validity of Papanicolaou smears. New York Cervical Disease Study. Obstet Gynecol. 1994; 84 (4): 591-597.
[24] Ellerbrock TV, Chiasson MA, Bush TJ, Sun X-W, Sawo D, Brudney $\mathrm{K}$, et al. Incidence of cervical squamous intraepithelial lesions in HIV-infected women. Jama. 2000; 283 (8): 1031-1037.

[25] Zhao F-H, Lewkowitz AK, Hu S-Y, Chen F, Li L-Y, Zhang Q-M, et al. Prevalence of human papillomavirus and cervical intraepithelial neoplasia in China: A pooled analysis of 17 population-based studies. Int J Cancer. 2012; 131 (12): 2929 2938.

[26] Verguts J, Bronselaer B, Donders G, Arbyn M, Van Eldere J, Drijkoningen $M$, et al. Prediction of recurrence after treatment for high-grade cervical intraepithelial neoplasia: the role of human papillomavirus testing and age at conisation. BJOG Int J Obstet Gynaecol. 2006; 113 (11): 1303-1307.

[27] Chang F, Syrjänen S, Shen Q, Ji H, Syrjänen K. Human papillomavirus (HPV) DNA in esophageal precancer lesions and squamous cell carcinomas from China. Int J Cancer. 1990; 45 (1): 21-25.

[28] Woo YJ, Yoon HK. In situ hybridization study on human papillomavirus DNA expression in benign and malignant squamous lesions of the esophagus. J Korean Med Sci. 1996; $11(6): 467-73$

[29] Toki T, Yajima A. "HPV score", a scoring system for histological diagnosis of human papillomavirus infection in dysplasia of the uterine cervix. Pathol Int. 1987; 37 (3): 449455.

[30] Missaoui N, Hmissa S, Sankaranarayanan R, Deodhar K, Nene B, Budukh A, et al. La surexpression de p16 INK4A est un marqueur utile des lésions du col utérin. In: Annales de biologie clinique. 2010. p. 409-414.

[31] Tjalma WA, Weyler JJ, Bogers JJ, Pollefliet C, Baay M, Goovaerts GC, et al. The importance of biological factors (bcl-2, bax, p53, PCNA, MI, HPV and angiogenesis) in invasive cervical cancer. Eur J Obstet Gynecol Reprod Biol. 2001; 97 (2): 223-230. 